\title{
Research on the Developmental Trend and Orientation of Marketing under the Internet and Multimedia Era
}

\author{
Yuanning Shi \\ Qinghai University of Finance and Economics College, XiNing 810016, China.
}

\begin{abstract}
This paper conducts research on the developmental trend and the orientation of marketing under the Internet and multimedia era. Network enables the commodity information to transfer to the consumers in the form of more efficient and convenient platform of social media has become a brand promotion. But in the digital era of information explosion, the consumer is more and more do not want to be spam. How to make digital marketing, let the brand communication with the consumers sincerely, building brand loyalty, become each enterprise is facing a big problem. To deal with the challenge, we propose novel perspective of the analysis on the marketing procedures that will enhance the result of marketing activities that will offer special significance.
\end{abstract}

Keywords: Multimedia era; developmental trend; orientation; marketing; internet features.

\section{Introduction}

Marketing is to find and create value a modern enterprise mode it is the modern enterprise to growing a necessary process. With the constant improvement of the information market in the new period, the original enterprise marketing mode cannot meet the needs of it become enterprise economic growth, the enterprise should go to the traditional marketing mode, innovation. Because marketing for timely, appropriate, with appropriate price for the products from producers to the consumers' hands, get the balance of production and consumption in time and region, to promote the social total supply and demand balance plays an important role. At the same time, market marketing to realize modernization in China, the development of our country in various fields of economy plays an enormous role [1-2].

According to the literature survey, the general procedures of the marketing could be organized as the follows. (1) Some of the economics of industrial organization theory to the marketing strategy has the important influence. Such as porter competitive advantage theory is that the manufacturer if able to produce a lower cost than its competitors, or in a unique way to create value for buyers as can obtain sustainable competitive advantage. (2) The establishment of the marketing channel is the division of labor in economics this basic principle reflected in the marketing. Channels of wholesalers, retailers or agent performs a different function, has the distribution of manufacturers have no skill. (3) As one of the promotion mix of public relations also has certain economic attributes. The basic function of system is to save transaction cost after the widespread social relationship contract series of general interpersonal contracts connected into network forms as a kind of institutional arrangement (Fig. 1).

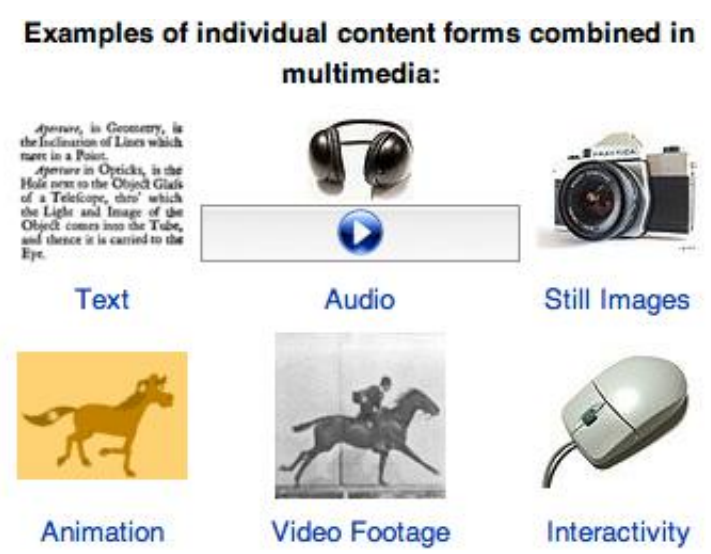

Fig. 1 The General Features of the Internet and Multimedia Era 
In the digital age, as the brand marketing is no longer a business owners spoon-feed to the user that simple, and pay more attention to create demand through interaction, attaches great importance to the enterprise together with the users set up long-term continuous interaction, common brand. In social system, the status of the digital Marketing Department was further promoted, and it will eventually become the enterprise organization structure of the data center. Rapid development of the science and technology, changing people's way of life and the way of communication, for the marketers, profound influence to promote products or services at the end of the day because the market has already turned into the intelligence network. In the later sections, we will discuss the issues in detail.

\section{Our Proposed Methodology}

\subsection{Basic Characteristics of the Marketing.}

Under the situation of the global economic integration, the market marketing idea deeply and each big enterprise, many marketing researchers gradually find that the concept of the marketing is not able to fully explain the described its essence, the definition of marketing is not perfect enough. Although the definition of marketing mentioned the importance of market demand, but also its weakness in here, because this definition ignores the demands of the core enterprise itself, attaches great importance to the enterprise of social responsibility.

A comprehensive understanding of the modern market marketing essence, which is beneficial to provide theoretical basis for the evaluation of enterprise marketing activities that high quality of the enterprise marketing activities, not only can bring higher economic benefits for the enterprise but also should create a good social benefits for enterprise. Every enterprise implementation of the marketing activities should include two parts, the content of the part is to set up the correct core values, not only to improve the economic benefits of enterprises as should also meet the needs of the enterprises in the aspect of spirit and goals. According to the survey can be found that some of the long-term company history that have been set up in its core value system, a sound has been agreed that the core values of the enterprise staff. Enterprises should break through the bondage of traditional management mode, set up modern marketing concept, adopt diversified modern enterprise marketing means, to avoid acts of unfair competition in marketing, in order to safeguard the interests of the enterprise, and from the perspective of consumer demand to develop a reasonable marketing strategy (Fig. 2).

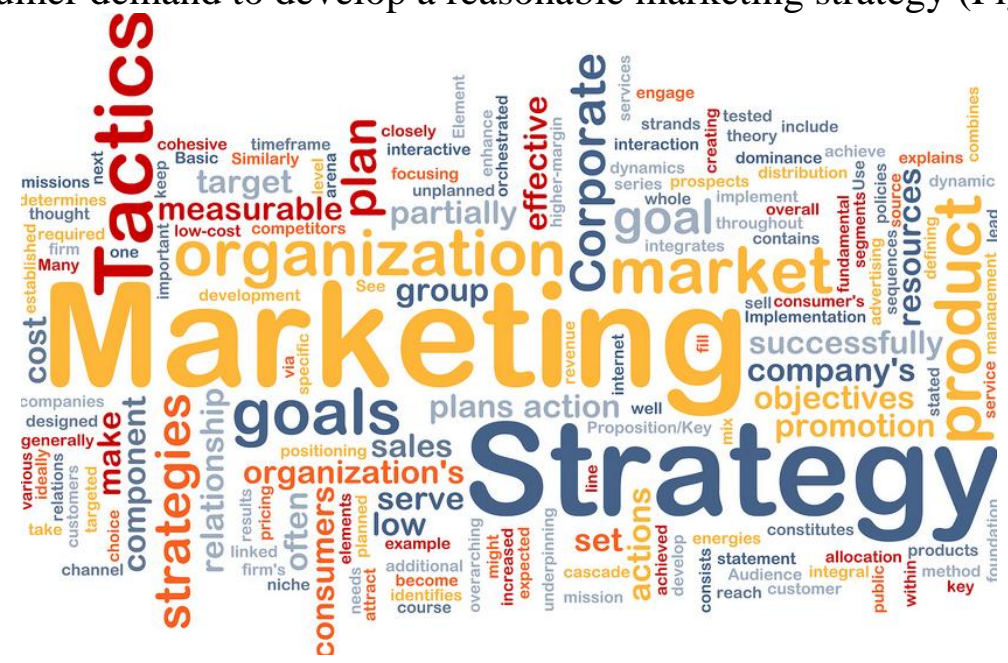

Fig. 2 The Keywords of the Marketing Activities

\subsection{The Digital Marketing.}

Digital marketing data mining of power from the Baidu and the CCTV's advertising turnover contrast can be revealed, and as the improvement of software and hardware, the smartphone has that gradually replaced the computer as today the most frequently used tool on the Internet. Communication channels and information receiving terminal change to subvert the original mode of transmission media as broke the life habits of people inherent mobile Internet has become the main growth point of the Internet users and business [3]. 
Digital media has changed the situation of basic asymmetric information, consumers can through the Internet before buying now solution aspects related information; Digital media also gives voice to consumer they can be published on the Internet about the opinions of the brand and product compared with the other countries, especially compared with the United States, the Internet more widely some implications to Chinese consumers. More functional for American consumers, the Internet, they buy tickets via the Internet, payment or shopping, occasionally there are some entertaining elements, but not many. But for Chinese consumers, the Internet is more entertaining. Relative to the traditional media of newspapers, magazines, the western countries for many years, traditional media in China for short, controlled by the government is strict, so take the network as representative of the new media power is strong, this is another feature of the Internet in China. Therefore, consumers more dependent on the Internet to watch the news, or interactive entertainment, the ratio is higher than other countries.

Digital marketing will become the center of gravity to promote marketing development should pay more attention to digital activity most marketing budget. Each company will increase investment in digital marketing and social media, to influence consumer purchase intention of individual effective influence and restriction role and give consumers a full range of positive effects. Due to consumption intention is gradually digital mining work and the marketing department at the same time promotes consumption intention to cultivate the digitization and automation. The Marketing Department shall formulate a similar factory assembly line work processes, the consumption intention into a real deal.

\subsection{Internet Marketing.}

Precision marketing is on the basis of fully understanding of the consumer information, according to its characteristics and preferences targeted to carry out the basic one-to-one marketing. Mobile Internet users are mostly fixed which can be the new network technology in-depth insight into the consumer interest and demand, and to establish for each specific customer database. Based on the analysis of customer data, then according to the characteristics of different customers and the preference information such as the precision marketing, at the same time can also according to customer's feedback information targeted adjustment of products and marketing, in order to better meet the needs of the customers that can be reflected from the listed aspects.

$>$ There are always some people value idea of imitation object, the object of imitation often lead a group behavior, then this group known as the reference group.

$>$ Internet education website as word-of-mouth channel no design fees, no use, it only requires the enterprise to do work is regularly and timely to the current business marketing initiatives.

$>$ The phenomenon of word-of-mouth is not die the enterprise management is not only to stop it. In fact, if an enterprise has more unique products that can use some channels to guide, promote and control the formation and basic development of rap that make it serve for the enterprise development strategy.

$>$ Dissemination of information is human nature often exchange purchase and use experience of the consumer goods, not only will introduce each other shopping sites, is introduced to buy and choose the goods experience recommend brands, product performance and to recommend specific products can also spread the product using the experience of failure or bad feelings, the spread of this kind of relationship, is not to need to cost, or only need very little cost.

The content of the mobile Internet marketing will become more diversified. With the development of mobile Internet technology and the increase of mobile terminal products, mobile Internet marketing in marketing tools and means, great changes will have on the content of the mobile Internet marketing will be diversified development trend. Small and the medium-sized enterprises not only can use the mobile Internet dissemination of product information, also can undertake data research, after-sales service and customer management, etc., and through the mobile Internet marketing further integration of enterprise's internal and external resources, realize the integrated marketing.

\subsection{The Multimedia Marketing.}

In today's high technology and new technology rapid development, China's media industry is undergoing profound changes its performance is characterized by rapid rise and rapid development of new media and traditional media between competing with each other. The rise of new media, the impact on the environment of the traditional media advertising, for the spread of traditional 
advertising and marketing has brought earth-shaking changes, advertising, content, the form of presentation are very different from the past [4].

Different from the emphasis of the traditional media, new media consumers become the important core of the advertising industry, advertisers degree deepen to the attention of the consumer demand, and began to make use of the SNS, Weibo, mobile phone media such as interactive attract consumers to participate in, using different media types, characteristics of the collaborative provides information to create an open platform, attract consumers to actively make their own annotations to brand content, give the connotation of the brand more deeply. In this era of everyone media, the word of mouth from sharing has become a force to be reckoned with in brand communication.

With market competition increasing multimedia business competition heats up make multimedia business price space narrowing. Therefore, the price must be in the limited space, use price leverage on the basis of the reasonable pricing rather than rely on price means to develop the user. But on the premise of marketing in accordance with the law while according to the market segmentation take the appropriate combination of marketing, characteristic, application and marketing strategy. New media almost carried the traditional media can carry a variety of forms, such as text, images, audio, video, etc., with its completely personalized information service can reach thousands of people at the same time that almost completely subvert the traditional media transmission of single mode and realize the two-way transmission of information, multidirectional communication. In the new media era of basic digital and network parallel, audience further differentiation, in the absence of rationality, an inherent limitation in process of information communication, the highlighting of the nature of interpersonal communication and strengthening, the original under the traditional media of the audience began to split into small groups of the like-minded or a stake, such as various types of the online gaming group, outdoor BBS, such as photography club. New media caught the specific group of consumption and the psychological needs, is more advantageous to achieve better communication effect.

\section{Conclusion}

In this paper, we conduct analysis on the developmental trend and the orientation of marketing under the Internet and multimedia era. Mobile Internet marketing if the lack of precision, and will cause a lot of cost, and big data era brought vast amounts of data to the mobile Internet marketing using multiple platforms to obtain information about the audience, the audience to spread more individuation, high correlation product information and at the same time, the portability of mobile devices make accurate marketing more timely. In the era of the mobile Internet, mobile Internet marketing will become the important content of enterprise marketing activities, only the correct grasp the development trend of mobile Internet marketing, using marketing strategies to grasp advantages in the fierce competition in the market, promote the competitiveness of the small and medium-sized enterprises. Our research combines the primary theories of the Internet marketing to propose new perspective of developmental trend and the orientation of marketing that is innovative.

\section{References}

[1] McKenzie-Mohr, Doug. Fostering sustainable behavior: An introduction to community-based social marketing. New society publishers, 2013.

[2] Hair, Joe F., et al. "An assessment of the use of partial least squares structural equation modeling in marketing research." Journal of the academy of marketing science 40.3 (2012): 414-433.

[3] Achrol, Ravi S., and Philip Kotler. "Frontiers of the marketing paradigm in the third millennium." Journal of the Academy of Marketing Science 40.1 (2012): 35-52.

[4] Zwerina, Klaus. Discrete choice experiments in marketing: use of priors in efficient choice designs and their application to individual preference measurement. Springer Science \& Business Media, 2013. 